\title{
Pengayaan Potensi Karir Melalui Webinar Sukses Berkarir dan Berwirausaha di Masa Sulit
}

\author{
Yenni Merlin Djajalaksana $^{\# 1}$, Doro Edi ${ }^{\# 2}$, Julianti Kasih ${ }^{* 3}$ \\ \#Program Studi Sistem Informasi,Universitas Kristen Maranatha \\ Jl. Surya Sumantri No. 65, Bandung \\ 1yenni.md@maranatha.ac.id \\ 2doro.edi@maranatha.ac.id \\ *Program Studi Teknik Informatika, Universitas Kristen Maranatha \\ Jl. Surya Sumantri No. 65, Bandung \\ 3julianti.kasih@maranatha.ac.id
}

\begin{abstract}
Abstrak - Pandemi Covid-19 mengakibatkan banyak bisnis yang mengalami masa sulit di mana pendapatan menurun tajam dan bahkan terpaksa harus menutup bisnisnya. Bisnis yang bertahan yang harus dapat tetap menjaga kelangsungan hidup perusahaan dengan melakukan penghematan baik mengurangi karyawan maupun melakukan hiring freeze atau berhenti merekrut karyawan baru untuk sementara. Akibatnya, kondisi ini menjadi tantangan bagi para lulusan Universitas di seluruh Indonesia, dengan berkurangnya lapangan kerja untuk memulai karir mereka. Sehubungan dengan hal ini, sebagai wujud pengabdian kepada masyarakat maka Fakultas Teknologi Informasi Universitas Kristen Maranatha mengadakan pengayaan potensi karir melalui Webinar gratis dengan mengundang para praktisi dari perusahaan-perusahaan teknologi untuk berbagi kiat-kiat dalam "Sukses Berkarir di Bidang Teknologi Informasi dan Berwirausaha di Masa Sulit". Praktisi ini adalah alumni dari Fakultas Teknologi Informasi Universitas Kristen Maranatha yang telah berkarir di berbagai perusahaan serta berwirausaha dengan sukses melewati masa sulit ini, yang sekaligus membuka kesempatan dan lowongan bagi masyarakat yang berminat untuk mencari kerja. Webinar ditargetkan kepada peserta para alumni, mahasiswa yang akan lulus, dan calon mahasiswa dari kalangan SMA untuk mendengarkan potensi karir di bidang Teknologi Informasi. Webinar telah berhasil dilaksanakan dengan pendaftar sejumlah 675 orang dan yang hadir sejumlah 383 orang $(+/-$ $56 \%$ ). Acara ini juga telah terpublikasi di YouTube dan MCU News agar lebih banyak lagi peserta yang dapat menerima manfaatnya.
\end{abstract}

Kata kunci-bisnis IT, karir IT, pandemi Covid-19, wirausaha, webinar

Abstract-The Covid-19 pandemic has resulted in many businesses experiencing hard times whose income had fallen sharply, and a large number of companies were forced to close their businesses. Businesses that survive must maintain the company's survival by cost savings, either by reducing employees, hiring freeze, or temporarily stopping hiring new employees. As a result, this condition becomes a challenge for university graduates across Indonesia, with fewer job opportunities to start their careers. In this regard, as a form of community service, the Faculty of Information Technology, Maranatha Christian University, held a career potential enrichment in the form of a free webinar inviting practitioners from technology companies to share tips on "Successful Career in Information Technology and Entrepreneurship in Difficult Times." Practitioners are alumni of the Faculty of Information Technology Maranatha Christian University. They have successful careers in various companies or own an entrepreneurial business that successfully went through this difficult time. They also came by opening up opportunities and vacancies for people who were interested in the job opportunities. The webinar targeted alumni, graduating students, and prospective high school students to hear about potential careers in Information Technology and entrepreneurship. The webinar was successfully held with 675 registrants and 383 people attending $(+/-56 \%)$. The event has also been published on YouTube and MCU News to be exposed to a larger audience for their benefit.

Keywords - Covid-19 pandemic, entrepreneurship, IT business, IT career, webinar

\section{PENDAhUluan}

Pandemi Covid-19 telah menciptakan situasi yang sangat sulit bagi semua area aspek kehidupan di Indonesia. Hal paling besar yang terjadi adalah dampak terhadap kondisi ekonomi negara Indonesia, di mana bisnis-bisnis baik bisnis berskala besar maupun kecil terpukul dengan adanya Lockdown, Pembatasan Sosial Berskala Besar (PSBB), dan Pemberlakuan Pembatasan Kegiatan Masyarakat (PPKM) untuk mengurangi laju penyebaran Covid-19. Banyak bisnis 
yang harus mengalami masa sulit di mana pendapatan menurun tajam sedangkan untuk tetap menjaga kelangsungan hidup perusahaan, mereka harus melakukan penghematan baik mengurangi karyawan maupun melakukan hiring freeze atau berhenti merekrut karyawan baru untuk sementara [1] [2] [3].

Berikut ini adalah bidang-bidang yang terdampak Pandemi Covid-19 berdasarkan data dari Januari - April 2020 [4]:

1. Pendidikan Dasar, Menengah, dan Tinggi terdampak besar dengan adanya pembelajaran yang dilaksanakan di rumah, namun secara positif bisnis dan organisasi di industri ini masih dapat menjalankan kegiatan operasional dan usahanya.

2. Perdagangan - terdampak besar dengan adanya pembatasan usaha, yang memaksa sebagian besar untuk menggunakan e-commerce bagi para pelaku usaha yang mana bersambut baik karena konsumen yang harus banyak tinggal di rumah meningkatkan belanjanya melalui antarmuka $e$-commerce.

3. Angkutan Online - karena tidak adanya lalu lintas orang sebagaimana biasanya, maka angkutan online mengalami penurunan transaksi yang signifikan

selama Pandemi Covid-19 [5]. Hasil dari penelitian ini adalah masyarakat memanfaatkan teknologi informasi dan komunikasi untuk tetap melaksanakan kegiatan karena fasitilas dan fitur dari teknologi informasi dan komunikasi yang memiliki keunggulan dan kemudahan untuk dipergunakan oleh berbagai kalangan masyarakat [5] [6].

Sedangkan dampak Pandemi Covid-19 yang berhubungan dengan tenaga kerja dapat dilihat dari penelitian Middia dan tim [7] serta tulisan dari Ruspendi [8], yang menyimpulkan bahwa Pandemi Covid-19 telah berdampak pada beberapa sektor, termasuk ketenagakerjaan. Bahkan Bapenas memprediksi bahwa Tingkat Pengangguran Tetap (TPT) akan meningkat hingga 2021 seiring dengan meluasnya dampak Pandemi Covid-19.

\section{MASALAH}

Kondisi yang telah diuraikan pada pendahuluan menjadi tantangan bagi para lulusan universitas di seluruh Indonesia, dengan berkurangnya lapangan kerja untuk memulai karir para lulusan .

Sehubungan dengan ini, maka Fakultas Teknologi Informasi Universitas Kristen Maranatha mengadakan pengayaan potensi karir melalui Webinar yang mengundang para praktisi dari perusahaan-perusahaan Teknologi untuk berbagi kiat-kiat dalam "Sukses Berkarir di Bidang Teknologi Informasi dan Berwirausaha di Masa Sulit". Praktisi ini adalah alumni dari Fakultas Teknologi Informasi sendiri yang telah bekerja di berbagai bidang atau namun kemudian cukup terbantu dengan kemitraan bersama berbagai bisnis yang menyediakan bahan pokok.

4. Perhotelan - dampak yang luar biasa berat, karena banyak terjadi pembatalan perjalanan sehingga area bisnis ini menjadi terpuruk.

5. Pariwisata - berbagai tempat wisata ditutup sepenuhnya, mengakibatkan para pelaku usaha kecil menengah yang mengandalkan atraksi wisata tersebut menjadi terdampak sangat signifikan.

6. Farmasi dan Kebutuhan Kesehatan - bisnis ini justru berkembang dengan adanya peningkatan produksi dan konsumsi.

Selanjutnya masih menurut Taufik dan Ayuningtyas [4], bidang-bidang bisnis yang berkembang setelah adanya Pandemi Covid-19 adalah telekomunikasi, penyedia/ vendor platform online, farmasi, produk Kesehatan melalui penyesuaian platform bisnis berbasis online.

Hal tersebut didukung dengan penelitian Rita Komalasari yang bertujuan mengetahui bagaimana masyarakat memanfaatkan teknologi informasi dan komuniasi sebagai media untuk meneruskan kegiatan yang tidak dapat dilakukan secara tatap muka dan teknologi yang dapat dimanfaatkan untuk kegiatan medis

memiliki bisnis sendiri, dan ditujukan kepada peserta para alumni, mahasiswa yang akan lulus, dan calon mahasiswa dari kalangan SMA untuk mendengarkan potensi karir di bidang Teknologi Informasi.

Webinar ini juga ditujukan bagi masyarakat luas, terutama bagi mereka yang membutuhkan tambahan wawasan mengenai lapangan pekerjaan di bidang IT. Diharapkan Webinar ini dapat membantu mereka untuk membuat strategi dalam mencari pekerjaan yang semakin sulit diakibatkan adanya pandemi Covid-19.

Webinar sukses berkarir ini juga memiliki tujuan secara khusus sebagai berikut:

a. Bagi masyarakat luas, alumni dan mahasiswa Fakultas Teknologi Informasi (IT), tujuan Webinar adalah memberikan edukasi kepada alumni dan calon alumni Fakultas IT terutama yang sedang mencari pekerjaan, untuk dapat menyusun strategi dalam mencari kerja di bidang IT dengan lebih baik.

b. Bagi calon mahasiswa atau siswa SMA, tujuan Webinar adalah memberikan edukasi kepada calon mahasiswa terutama yang berminat pada bidang IT untuk membantu memilih program studi yang sesuai di bidang IT dengan lebih baik.

c. Bagi dosen dan anggota panitia mahasiswa yang terlibat dalam pengabdian masyarakat, Webinar bertujuan sebagai wujud dari pelaksanaan Tridharma 
d. Perguruan Tinggi dan memberikan dampak yang luas dan berguna bagi masyarakat melalui sharing ilmu pengetahuan.

e. Bagi Universitas Kristen Maranatha, Webinar merupakan wujud kepedulian institusi terhadap kebutuhan alumni, mahasiswa, dan masyarakat.

\section{METODE PELAKSANAAN}

Metode yang dilakukan dalam Webinar ini adalah sebelumnya melakukan pembentukan panitia Webinar, kemudian melakukan diskusi dan koordinasi terlebih dahulu dengan para pembicara yang merupakan alumni Fakultas Teknologi Informasi. Pembahasan terkait dengan rencana, tujuan dan sasaran kegiatan Webinar sukses berkarir di bidang Teknologi Informasi di masa sulit.

Selanjutnya kegiatan Webinar dilaksanakan dengan tahapan-tahapan sebagai berikut:

1. Pembuatan proposal pengabdian masyarakat

2. Pembuatan desain promosi acara

3. Persiapan Webinar

4. Pelaksanaan Webinar

5. Evaluasi dan Survey Peserta

\section{A. Pembicara}

Pembicara Webinar adalah alumni Fakultas Teknologi Informasi yang telah bekerja di berbagai bidang ataupun memiliki bisnis sendiri. Nama dan data pembicara Webinar dapat dilihat pada Tabel 1 .

\section{Tabel 1. Daftar Pembicara Webinar Sukses Berkarir}

\begin{tabular}{|l|l|l|l|}
\hline Industri & Perusahaan & Nama dan Gelar & Posisi/ Jabatan \\
\hline Fintech & Brankas & $\begin{array}{l}\text { Marolop L. David } \\
\text { Siagian, S.Kom. }\end{array}$ & Product Manager \\
\hline $\begin{array}{l}\text { E- } \\
\text { Commerce }\end{array}$ & Blibli & $\begin{array}{l}\text { Lois Amilia, } \\
\text { S.Kom. }\end{array}$ & $\begin{array}{l}\text { Associate } \\
\text { Operation Project } \\
\text { Management } \\
\text { Manager }\end{array}$ \\
\hline Fintech & $\begin{array}{l}\text { PayPay } \\
\text { Corporation }\end{array}$ & $\begin{array}{l}\text { William Surya } \\
\text { Setiadi, S.Kom. }\end{array}$ & $\begin{array}{l}\text { Software } \\
\text { Engineer }\end{array}$ \\
\hline Logistic & SiCepat & $\begin{array}{l}\text { Martha Sutopo, } \\
\text { S.Kom. }\end{array}$ & $\begin{array}{l}\text { Senior Backend } \\
\text { Developer }\end{array}$ \\
\hline $\begin{array}{l}\text { Digital } \\
\text { Agency }\end{array}$ & $\begin{array}{l}\text { Boleh } \\
\text { Dicoba }\end{array}$ & $\begin{array}{l}\text { Muhammad Rizki } \\
\text { Fahrurrozi, } \\
\text { S.Kom., MM }\end{array}$ & CEO dan Founder \\
\hline $\begin{array}{l}\text { Renewable } \\
\text { Energi }\end{array}$ & BK Group & $\begin{array}{l}\text { Djono Albar } \\
\text { Burhan, S.Kom., } \\
\text { MMgt (Int.Bus) }\end{array}$ & CEO \\
\hline
\end{tabular}

Adapun Moderator Webinar juga berasal dari alumni Fakultas Teknologi Informasi yaitu seperti yang terlihat pada Tabel 2.

Tabel 2. Moderator Webinar Sukses Berkarir

\begin{tabular}{|l|l|l|l|}
\hline Industri & Perusahaan & Nama dan Gelar & Posisi/ Jabatan \\
\hline Banking & PT. Bank & Seruni Dewanti, & IT Project \\
& Rakyat & S.Kom. & Officer/ QA \\
& Indonesia, Tbk & & Engineer \\
\hline
\end{tabular}

\section{B. Peserta}

Target utama acara Webinar adalah dengan prioritas sebagai berikut:

1. Alumni dan Calon Alumni (mahasiswa yang hampir lulus) Fakultas Teknologi Informasi yang saat ini sedang membutuhkan pekerjaan atau sedang mencari pekerjaan di bidang IT.

2. Siswa SMA yang masih sedang menentukan pilihan program studi dan ingin mengetahui potensi karir di bidang IT

3. Masyarakat luas yang sedang mencari pekerjaan di bidang IT.

Pendaftaran Webinar dilakukan dengan menggunakan Google Form dan dipublikasikan melalui berbagai Media Sosial Instagram Feed dan Story @itmaranatha, @ universitaskristenmaranatha, @ belajarsisfo, @ simaranatha, @webinar.gratis dan Instagram personal dari setiap anggota panitia dan pembicara.

Informasi Webinar juga disebarkan melalui Whatsapp dan Telegram ke Group yang relevan, Website it.maranatha.edu dan belajarsisfo.net, serta Facebook Pages. Upaya ini telah berhasil mengumpulkan 675 pendaftar.

\section{Pelaksanaan Webinar}

Pelaksanaan pengabdian masyarakat melalui webinar ini telah berhasil dilaksanakan pada Hari Sabtu, tanggal 24 April 2021, pukul 10.00-12.15 WIB.

Penyelenggaraan dilakukan secara daring dengan menggunakan media Zoom milik Fakultas Teknologi Informasi sesuai dengan waktu yang telah ditentukan dan dengan kapasitas maksimum 300 orang, selebihnya peserta juga dapat mengikuti Webinar melalui YouTube Channel Fakultas Teknologi Informasi

(https://www.youtube.com/watch?v=4X8AeqsOLp0\&t=84 49s) secara live.

Hasil akhir dari pelaksanaan pengabdian masyarakat ini adalah bertambahnya pengetahuan dan wawasan bagi alumni, calon alumni, siswa SMA dan masyarakat mengenai kiat-kiat dalam "Menghadapi Masa Sulit untuk Berkarir dan Berwirausaha untuk bidang Teknologi Informasi”.

\section{HASIL DAN PEMBAHASAN}

Kegiatan Webinar diawali dengan persiapan pelaksanaan kegiatan, yaitu melakukan promosi kegiatan Webinar, mendata pendaftar, mengirimkan reminder ke pendaftar sebelum pelaksanaan Webinar melalui email maupun pesan Whatsapp.

\section{A. Agenda Pelaksanaan}

Pelaksanaan Webinar dilaksanakan pada hari Sabtu, 24 April 2021 dengan agenda pada Tabel 3. 
Tabel 3. Agenda Webinar Sukses Berkarir

\begin{tabular}{|l|l|}
\hline \multicolumn{1}{|c|}{ Waktu } & \multicolumn{1}{|c|}{ Acara } \\
\hline $9.30-10.00$ & Ruang Zoom Dibuka \\
\hline $10.00-10.03$ & MC menyapa peserta \\
$10.03-10.08$ & Kata sambutan Dekan FIT \\
& Moderator (Seruni Dewanti, S.Kom.) memimpin \\
\hline $10.08-10.10$ & acara \\
\hline $10.10-10.20$ & Pembacaan CV Singkat Pembicara 1 (1 menit) \\
& Pidato Pembicara 1: Marolop L. David Siagian, \\
& S.Kom. \\
\hline $10.20-10.30$ & Pembacaan CV Singkat Pembicara 2 (1 menit) \\
& Pidato Pembicara 2: Lois Amilia, S.Kom. \\
\hline $10.30-10.40$ & Pembacaan CV Singkat Pembicara 3 (1 menit) \\
& Pidato Pembicara 3: William Surya Setiadi, \\
& S.Kom. \\
\hline $10.40-10.50$ & Pembacaan CV Singkat Pembicara 4 (1 menit) \\
& Pidato Pembicara 4: Martha Sutopo, S.Kom. \\
\hline $10.50-11.00$ & Pembacaan CV Singkat Pembicara 5 (1 menit) \\
& Pidato Pembicara 5: Muhammad Rizki Fahrurrozi, \\
\hline
\end{tabular}

walaupun masa sulit ini tiba [9] [10].

Berikut ini adalah kiat yang dibagikan para pembicara untuk berkarir di bidang IT agar bisa sukses:

1. Bekerjalah di Start-Up

Lois memaparkan bahwa saat lulus kemudian bekerja di Blibli yang sebetulnya sangat sulit untuk dijelaskan karena saat itu Blibli belumlah dikenal karena merupakan Start-up. Sempat Lois menggunakan deskripsi "Blibli yang seperti Untuk Bidang IT, beliau menyarankan Start-Up bisa jadi pilihan untuk karir Bidang IT karena perkembangannya sangat cepat, bisa berperan sebagai "change maker", berpotensi mendapatkan recognition, berada dalam lingkungan yang inovatif dan untuk salary juga sangat baik. Dengan berkembang bersama Start-Up memang banyak risiko, namun sangat "worth-it" untuk bidang IT.

2. Networking

Kunci untuk membuka pintu untuk sebuah lowongan kerja adalah kenal dengan para karyawan yang sudah bekerja di dalamnya. Pengalaman Marolop saat memulai karir setelah lulus S1 adalah kenal dengan karyawan Blibli yang dikenal dari networking sebelumnya. Pentingnya networking juga dikonfirmasi oleh William yang saat ini bekerja di Jepang, karena dengan adanya networking setidaknya CV akan diutamakan untuk dipertimbangkan, dibandingkan hanya sekedar melamar lewat jalur biasa.

lagi melalui berbagai sertifikat.

6. Passion dan Keinginan Kuat

Martha menyarankan bahwa untuk dapat mengembangkan karir di IT, sangat penting untuk menemukan Passion, apa yang disukai untuk bekerja, dan mendalami keahlian itu. Dengan trend IT sekarang, begitu banyak perkembangan

\begin{tabular}{|l|l|}
\hline \multicolumn{1}{|c|}{ Waktu } & \multicolumn{1}{c|}{ Acara } \\
\hline & S.Kom., MM \\
\hline $11.00-11.10$ & $\begin{array}{l}\text { Pembacaan CV Singkat Pembicara 6 (1 menit) } \\
\text { Pidato Pembicara 6: Djono Albar Burhan, S.Kom., } \\
\text { MMgt (Int. Bus) }\end{array}$ \\
\hline $11.10-11.15$ & Photo Bersama/ Dokumentasi \\
\hline $11.15-11.50$ & $\begin{array}{l}\text { Diskusi Panel - 6 Pembicara siap menanggapi } \\
\text { Pertanyaan }\end{array}$ \\
\hline $11.50-11.55$ & $\begin{array}{l}\text { Pemberian Sertifikat Penghargaan pada Para } \\
\text { Pembicara }\end{array}$ \\
\hline $11.55-12.00$ & Penutupan Acara oleh Ketua Panitia \\
\hline
\end{tabular}

\section{B. Intisari Pengetahuan pada Webinar}

Berbagai kiat diberikan oleh para pembicara (Daftar pembicara dapat dilihat pada Tabel 1) yang tergolong masih muda dengan pengalaman antara 6 sampai 8 tahun telah melesatkan karir dan usaha mereka

3. Kemampuan Komunikasi dan Interview Kerja William menyatakan bahwa kemampuan komunikasi dan interview itu keharusan, apalagi jika berminat untuk bekerja di luar negeri seperti dirinya. Ia menghabiskan waktu untuk belajar untuk menjawab pertanyaan-pertanyaan interview sampai yakin dan terbiasa untuk menjawab pertanyaan dengan percaya diri.

4. Menampilkan Profil CV yang Menonjol

Menampilkan CV yang bagus adalah kunci yang dipaparkan oleh Lois Amilia dari Blibli. Beliau mengatakan bahwa CV yang masuk begitu banyak, tentunya untuk dapat menarik perusahaan untuk memanggil interview adalah adanya $\mathrm{CV}$ yang menonjol. Oleh karena itu membuat CV tidak asalasalan, dan jangan lupa selama kuliah harus aktif dalam berbagai kegiatan seperti magang, berperan dalam organisasi Himpunan maupun Senat Mahasiswa.

5. Jujur atas Kemampuan

Marolop mengatakan bahwa sangat penting untuk jujur, maksudnya kalau tidak bisa kemampuan tertentu, janganlah mengakui bahwa bisa. Jujur saja, dan tunjukkan kemauan untuk belajar. Untuk itu, Marolop menekankan pentingnya investasi atas kemampuan diri sendiri, dan jika misalnya salah mengambil program studi pun, tetap masih bisa belajar

pengetahuan, dan untuk bisa semuanya mungkin tidak sempat, tetapi kalau mendalami beberapa dan fokus untuk pengembangannya, bisa mencari pekerjaan yang pas. Pastinya pekerjaan sebagai Developer IT sangat banyak dicari di saat ini.

7. Terus Belajar, Jangan Berhenti 
Martha dan William sama-sama mendorong agar setiap orang terus belajar tanpa henti, dan jika perlu harus "Learn How You Learn" lalu belajar, karena dunia IT adalah dunia tanpa batas, di mana perkembangan pengetahuan dan teknologi begitu pesatnya, sehingga kalau kita lalai belajar, pasti ketinggalan. Martha mengatakan bahwa saat ini teknologi Robot dan Artificial Intelligence, begitu pesatnya. Selama kita ada senjata "Laptop dan Internet", jangan pernah berhenti belajar dan berkarya karena kecepatan itu menjadi penting untuk bisa "survive".

Ketujuh elemen tersebut sangat penting bagi mereka yang ingin berkarir di Bidang IT. Sekarang, bagaimana dengan mereka yang minat membuka perusahaan atau juga membangun Start-Up di bidang IT atau bidang lainnya?

Paparan dari kedua wirausahawan muda menguak rahasia untuk keberhasilan Wirausaha Start-Up sebagai berikut:

1. Rencanakan matang, terutama Keuangan Djono berbagi kiat bahwa satu tahun pertama memulai usaha adalah sesuatu yang cukup berat dan juga riskan, dan kita selalu berpotensi untuk gagal atau tidak memiliki aliran kas yang cukup. Oleh karena itu, Djono yang saat ini adalah CEO BK Group menyarankan untuk wirausaha harus sudah ada perhitungan berapa dana yang dibutuhkan, dan bagaimana mendanainya. Ini menghindarkan kekalahan konyol karena kehabisan dana sebelum berkembang.

2. Mencari Klien dengan Bertarget setiap Bulannya Baik Rizki maupun Djono menyarankan bahwa wirausahawan itu harus mau bersusah payah berusaha untuk mencari klien, karena klien berarti aliran kas masuk. Tanpa aliran kas masuk, wirausaha kita akan siap-siap untuk kandas. Oleh karena itu, setidaknya Djono menyarankan "StartUp setidaknya harus dapat tambahan 1 klien per bulan untuk menstabilkan pendapatan”. Untuk itu Rizki juga mengingatkan bahwa marketing itu sudah wajib, baik tradisional maupun digital, untuk mencari klien demi kelangsungan hidup usaha start-up.

3. Fleksibilitas dan Kerja Ekstra

Perbedaan terbesar antara bekerja dengan memiliki usaha adalah, sebagai wirausahawan harus mau bekerja dengan fleksibel dan ekstra, demikian sambung Rizki, "Maksudnya, kalau klien memanggil malam-malam atau harus bekerja ekstra, apalagi Start-Up ya tetap harus dilakoni!" Demikian maka di awal awal usaha pastinya akan cukup melelahkan, tapi perlu diingat bahwa wirausaha berarti "Potential Unlimited Income" untuk masa depan.

4. Konsep MVP = Minimum Viable Product
Konsep Minimum Viable Product (MVP) adalah salah satu strategi pengembangan produk yang umumnya dilakukan oleh Start-Up. Djono menyarankan bahwa sebagai Start-Up harus bisa menentukan MVP dan meluncurkan produk yang dibuat itu secara bertahap. Mengapa ini harus dilakukan? "Karena dana yang dikucurkan pastinya akan terbatas, padahal kita harus segera menerima pendapatan." Maka produk bisa dibuat dalam beberapa tahap dibandingkan harus membuat produk yang sempurna. Rizki mendukung pernyataan ini, apalagi beliau juga mengalami sendiri sebagai Start-Up.

5. Untuk Start-Up, jangan pakai "Uang Panas"

Maksudnya bagaimana? Saran dari Djono, sangat penting untuk Start-Up untuk tidak memakai uang pinjaman dengan bunga tinggi seperti meminjam ke Bank atau meminjam ke Perusahaan Keuangan. Kalau bisa, carilah pinjaman lunak seperti dari keluarga, jika menggunakan uang pribadi tidak ada. Dengan meminjam, maka wirausaha Start-Up akan stress padahal tekanan dari luar sangat besar dan di awal-awal biasanya Start-Up tidak bisa menghasilkan pendapatan yang memadai.

\section{Dokumentasi Pelaksanaan}

Setelah uraian dari pembicara, acara Webinar dilanjutkan dengan tanya jawab secara panel dengan para pembicara. Gambar 1-3 berikut ini adalah dokumentasi pelaksanaan Webinar Sukses Berkarir di Bidang IT.

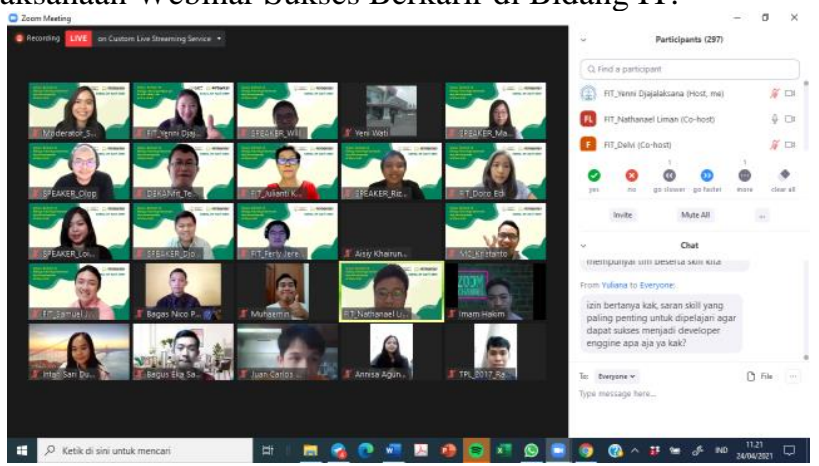

Gambar 1. Foto Bersama Kegiatan Webinar 


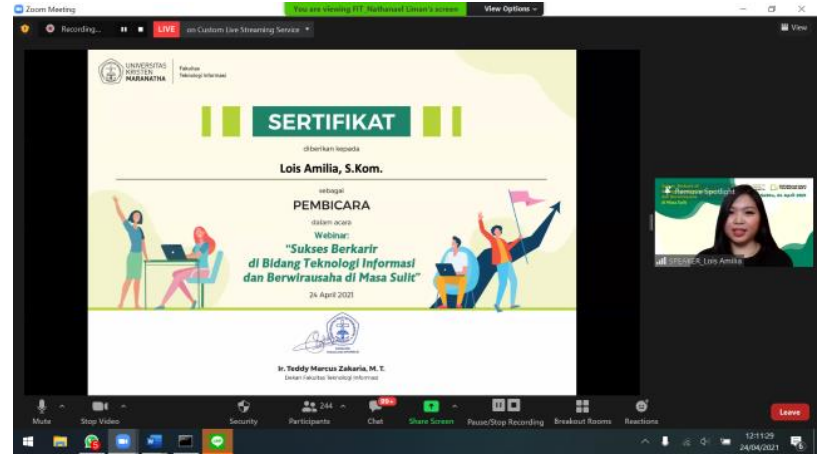

Gambar 2. Foto Pemberian Sertifikat Salah Satu Pembicara

\section{Evaluasi Pelaksanaan}

Pada akhir acara Webinar, dibagikan link Google Form presensi dan feedback yang diisi oleh peserta sebagai syarat untuk mendapatkan sertifikat. Form feedback diisi oleh sebanyak 380 peserta/ responden. Hasil pengisian form

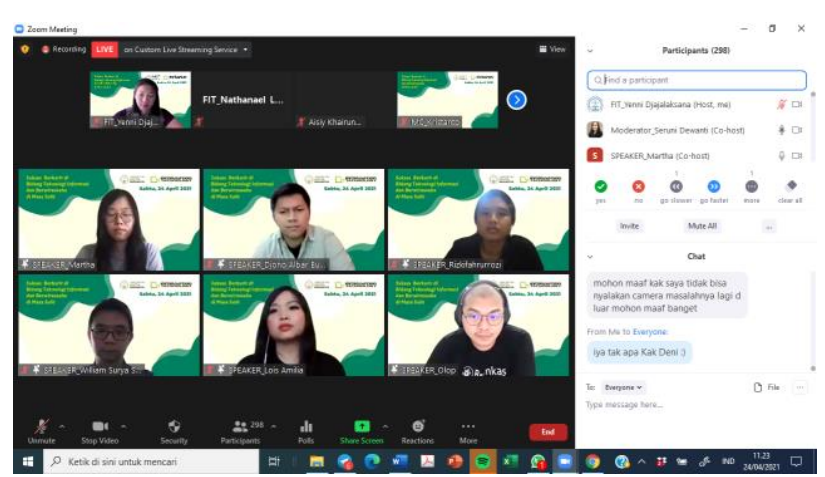

Gambar 3. Foto Tanya Jawab Panel

presensi dan feedback kemudian dievaluasi dan didapatkan hasil yang dapat dilihat pada Tabel 4. Dari hasil pengisian feedback pada Tabel 4, dapat dilihat bahwa keseluruhan acara Webinar dari sisi fasilitas, pembicara, materi dan waktu berjalan dengan baik.

Tabel 4. Hasil Pengisian Form Feedback Webinar

\begin{tabular}{|c|c|c|c|c|c|c|c|c|c|}
\hline \multirow{2}{*}{ Pertanyaan } & \multicolumn{2}{|c|}{ Sangat Setuju } & \multicolumn{2}{|c|}{ Setuju } & \multicolumn{2}{|c|}{ Kurang Setuju } & \multicolumn{2}{|c|}{ Tidak Setuju } & \multirow{2}{*}{$\begin{array}{c}\text { Total } \\
\text { Responden }\end{array}$} \\
\hline & Frekuensi & $\%$ & Frekuensi & $\%$ & Frekuensi & $\%$ & Frekuensi & $\%$ & \\
\hline $\begin{array}{l}\text { Fasilitas meeting online yang } \\
\text { digunakan berjalan dengan baik }\end{array}$ & 166 & 43.7 & 205 & 53.9 & 5 & 1.3 & 4 & 1 & 380 \\
\hline $\begin{array}{l}\text { Materi yang dibagikan } \\
\text { memberikan pengetahuan/insight } \\
\text { baru }\end{array}$ & 193 & 50.8 & 178 & 46.8 & 5 & 1.3 & 4 & 1 & 380 \\
\hline $\begin{array}{l}\text { Materi hari ini dapat diikuti } \\
\text { dengan baik }\end{array}$ & 174 & 45.8 & 198 & 52.1 & 4 & 1 & 4 & 1 & 380 \\
\hline $\begin{array}{l}\text { Pembicara menyampaikan materi } \\
\text { dengan baik }\end{array}$ & 187 & 49.2 & 181 & 47.6 & 8 & 2 & 4 & 1 & 380 \\
\hline Sesi Tanya Jawab berkualitas & 179 & 47.1 & 186 & 48.9 & 9 & 2.4 & 6 & 1.6 & 380 \\
\hline Waktu Webinar memadai & 151 & 39.7 & 209 & 55 & 15 & 3.9 & 5 & 1.3 & 380 \\
\hline
\end{tabular}

\section{E. Refleksi Kegiatan}

Kegiatan Webinar ini sangat bermanfaat bagi masyarakat, membantu membukakan wawasan pengetahuan untuk dunia karir bagi mereka. Selain itu, webinar ini juga sangat baik untuk menunjukkan kualitas dari para alumni dari Fakultas Teknologi Informasi Universitas Kristen Maranatha, dan dinilai memiliki manfaat yang positif oleh para peserta.

Kegiatan ini telah berhasil dengan baik, dalam persiapan, pelaksanaan, maupun materi dengan nilai tinggi untuk peserta. Peserta pun antusias dan banyak yang mendaftar serta hadir. Pengingat melalui Whatsapp kepada para peserta dinilai efektif membantu meningkatkan kehadiran peserta.
Mempertimbangkan semua itu, diharapkan kegiatan pengabdian masyarakat serupa dapat diadakan kembali di masa yang akan datang.

\section{F. Keberlanjutan Kegiatan}

Kegiatan Webinar ini dapat terus dilanjutkan sebagai kegiatan teratur, terjadwal setiap tahun sekali. Berdasarkan pengeluaran dana, kebutuhan dana pelaksanaan Webinar ini tidak terlalu tinggi, sehingga akan mudah untuk didanai oleh penyelenggara. Webinar dapat dilakukan terjadwal dilaksanakan sekitar bulan April, cukup cocok untuk meminta para calon lulusan dan para pencari kerja untuk menjadi peserta.

\section{KESIMPULAN}


Beberapa kesimpulan yang dapat diambil dari kegiatan pengabdian masyarakat berupa Webinar yang telah diuraikan adalah:

a) Pendaftar Webinar melalui Google Form sejumlah 675 orang, dimana sebagian besar yaitu $44.9 \%$ berasal dari Mahasiswa bukan Maranatha, disusul $17 \%$ pendaftar dari masyarakat umum.

b) Peserta Webinar yang hadir sejumlah 383 orang, kurang lebih $56 \%$ dari jumlah pendaftar.

c) Pendaftar Webinar mengetahui adanya acara Webinar ini sebagian besar dari Media Instagram yaitu sejumlah $59.9 \%$.

d) Sebanyak 380 Responden yang mengisi form feedback. Hasil pengisian menunjukkan lebih dari 90\% menyatakan acara Webinar dari sisi fasilitas, pembicara, materi dan waktu berjalan dengan baik.

e) Luaran dari pengabdian masyarakat ini adalah sebagai berikut:

1. Berita di MCU News:

http://news.maranatha.edu/mengenal-karier-dibidang-teknologi-informasi-bersama-ftimaranatha/

2. Publikasi Webinar di YouTube Channel: https://www.youtube.com/watch?v=4X8AeqsO $\mathrm{Lp} 0 \& \mathrm{t}=8449 \mathrm{~s}$

\section{UCAPAN TERIMA KASIH}

Terima kasih kepada Universitas Kristen Maranatha yang telah mendukung dana untuk pelaksanaan pengabdian masyarakat ini. Terima kasih juga kepada para alumni Fakultas Teknologi Informasi yang telah mendukung mensukseskan acara Webinar Sukses Berkarir di Bidang Teknologi Informasi di Masa Sulit.

\section{DAFTAR PUSTAKA}

[1] D. A. D. Nasution, Erlina and I. Muda, "Dampak Pandemi Covid-19 Terhadap Perekonomian Indonesia," Jurnal Benefita, pp. 212-224, 2020.
[2] A. F. Thaha, "Dampak Covid-19 Terhadap UMKM di Indonesia," Jurnal Brand, pp. 147-153, 2020.

[3] A. Amri, "Dampak Covid-19 Terhadap UMKM di Indonesia," Jurnal Brand, pp. 123-129, 2020.

[4] Taufik and E. A. Ayuningtyas, "Dampak Pandemi COVID-19 Terhadap Bisnis dan Eksistensi Platform Online," Jurnal Pengembangan Wiraswasta, pp. 21-32, 2020.

[5] R. Komalasari, "Manfaat Teknologi Informasi dan Komunikasi di Masa Pandemi Covid 19," TEMATIK - Jurnal Teknologi Informasi Dan Komunikasi, vol. 7, pp. 38-49, 2020.

[6] U. H. Salsabila, R. Zulaika, V. A. Arista and Y. W. Santoso, "Peran Teknologi Pendidikan Dalam Penggunaan E-Learning Sebagai Platform Pembelajaran Dimasa Pandemi Covid-19," Edureligia, vol. Vol. 04 N0.02, no. Universitas Ahmad Dahlan Yogyakarta, pp. 196-206, 2020.

[7] M. M. Dewi, F. Magdalena, N. P. D. Ariska, N. Setiyawati and W. C. Rumboirusi, "Dampak Pandemi Covid-19 Terhadap Tenaga Kerja Formal di Indonesia," Populasi, pp. 32-53, 2020.

[8] Ruspendi, "Dampak Pandemi Covid-19 Terhadap Dunia Usaha dan Persaingan Tenaga Kerja," Teknik Industri Universitas Pamulang, 18 Februari 2021. [Online]. Available:

http://industri.unpam.ac.id/dampak-pandemicovid-19-terhadap-dunia-usaha-dan-persaingantenaga-kerja/.

[9] "Maranatha News," Universitas Kristen Maranatha, 27 April 2021. [Online]. Available: http://news.maranatha.edu/mengenal-karier-dibidang-teknologi-informasi-bersama-ftimaranatha/.

[10] I. T. o. Maranatha, "YouTube Channel," 24 April 2021. [Online]. Available: https://www.youtube.com/watch?v=4X8AeqsOLp $0 \& \mathrm{t}=8449 \mathrm{~s}$. 